\title{
Os melhores empregados a inserção e a formação da mão-de-obra feminina em fábricas têxteis mineiras no final do século $\mathrm{XIX}^{\star}$
}

\author{
"The best employees" \\ the insertion and training of the female workforce in textile \\ factories in Minas Gerais State in the late $19^{\text {th }}$ century
}

\author{
JUNIA DE SOUZA LIMA \\ Doutoranda em História (PPGH/UFMG) \\ Professora substituta do Centro Federal de Educação \\ Tecnológica de Minas Gerais - CEFET/MG. Av. Amazonas 5.855 - \\ Nova Gameleira - Belo Horizonte - MG - Brasil - Cep: 30.510-000 \\ juniaslima@hotmail.com
}

\begin{abstract}
RESUMO Este artigo discute o processo de inserção e formação da mãode-obra feminina na indústria têxtil em Minas Gerais no final do século XIX, tomando para análise a Companhia de Fiação e Tecidos Cedro e Cachoeira. Como ocorrido em muitas outras fábricas têxteis, as mulheres foram durante muito tempo o maior conjunto de trabalhadores desta Cia. Trabalhando como fiandeiras e tecelãs, as operárias ingressavam, muitas vezes, ainda jovens, passando boa parte da vida dentro das fábricas, inseridas em um tipo de relação que Ihes ensinava a serem operárias e, ao mesmo tempo, as educava enquanto mulheres, a partir de determinados valores culturais, dentre os quais se destaca a religiosidade. Nesse sentido busca-se aqui refletir sobre como esse processo se materializava no cotidiano das fábricas, os aspectos aí envolvidos e suas principais implicações para a vida das trabalhadoras.
\end{abstract}

* Artigo recebido em: 24/08/2010. Aprovado em: 16/03/2011. 
Palavras-chave mulheres, trabalho, indústria têxtil

ABSTRACT This paper discusses the process of insertion and training of the female workforce in the textile industry in Minas Gerais State in the late nineteenth century, and for this purpose the Company of Textiles and Spinning Cedro e Cachoeira will be analyzed. As also happened in many other textile factories, women have been for a long time the largest group of employees of that Company. Working as spinners and weavers, the women often started working at a young age, spending much of their life inside the factories, being part of a relationship that taught them to be workers and at the same time, educated them from certain cultural values, being the religion a relevant issue in this context. In this sense, reflections will be searched in order to understand how this process occurred in the daily life of plants, the aspects involved and their main implications for the lives of workers.

Keywords women, labor, textile industry

Como sabes não convém que façamos mais casas; as que têm são suficientes, tanto mais que na proporção que alguma família se retira, a vou substituindo por moças do convento que são os melhores empregados

Francisco Mascarenhas ${ }^{1}$

\section{Introdução}

O objetivo desse texto é refletir sobre o processo de inserção e formação da mão-de-obra feminina em fábricas têxteis mineiras no final do século XIX. De forma mais precisa nos voltamos aqui para o cotidiano vivido pelas operárias buscando trazer à tona as relações às quais estavam submetidas, as suas condições de trabalho, suas principais tarefas e ocupações e os caminhos de sua formação para o trabalho têxtil fabril. Além disso, procuramos igualmente delinear um perfil social, cultural e econômico dessas operárias de forma, a saber, quem eram essas mulheres, de onde vinham, quais eram os motivos que as levavam para as fábricas, que desafios enfrentavam como operárias têxteis no dia-a-dia do trabalho fabril. Para isso tomamos como referência as fábricas pertencentes à Companhia de Fiação e Tecidos Cedro e Cachoeira (CCC), fundadas em Minas Gerais no final do século XIX. ${ }^{2}$

1 Trecho de uma carta escrita por Francisco Mascarenhas em 23/02/1887, quando ocupava o cargo de gerente da Fábrica da Cachoeira.

2 São as fábricas: Cedro, Cachoeira e São Vicente. 
As mulheres estiveram presentes nas fábricas capitalistas desde os primórdios do capitalismo na Inglaterra. Segundo dados apresentados por Eric J. Hobsbawm ${ }^{3}$ nas fábricas de tecidos inglesas em 1838 "apenas $23 \%$ dos trabalhadores das fábricas de tecidos eram homens adultos". No Brasil e Minas Gerais essa situação não se modifica muito. De acordo com Francisco Foot e Victor Leonardi ${ }^{4}$ o trabalho das mulheres ocupava um lugar significativo na composição da força de trabalho principalmente nos setores têxtil, do vestuário e do toucador a partir da segunda metade do século XIX.

No que se refere a Minas Gerais, Douglas Cole Libby ${ }^{5}$ avalia que 56,9\% da mão-de-obra de trabalhadores em fábricas têxteis mineiras no final do século XIX era composta por mulheres. Em pesquisa mais recente, Cristiane Maria Magalhães ${ }^{6}$ afirma que na Cia União Itabirana a partir de 1903, o número de mulheres e meninas empregadas excedia ligeiramente o número de operários do sexo masculino. Em relatório provincial datado de 02 de agosto de 1883 o Presidente da província mineira também constatou a primazia da força de trabalho feminina na indústria têxtil na província:

Um dos mais belos frutos da iniciativa individual, entre nós, são as fábricas de tecidos estabelecidas ao norte da província (...). Os brilhantes resultados d'esse nobilíssimo cometimento despertarão, nos municípios vizinhos, o espírito industrial e hoje conta a nossa província nove fábricas que elevam ao importante algarismo de cerca de 12:000 metros de panos a produção diária, e dão trabalho profissional e lucrativo a 700 operários, a máxima parte do sexo feminino. ${ }^{7}$

O que todos esses dados ajudam a reforçar é a importância da participação feminina no período do surgimento e da consolidação do capitalismo em diversas partes do mundo. Como operárias, centenas de mulheres enchiam as salas de fiação e tecelagem, trabalhando de sol a sol em jornadas de trabalho que chegavam a 12 horas diárias, dividindo com os homens o encargo da produção. Para muitas, o trabalho nas fábricas contribuía também para o sustento da família.

Diversos autores já se dispuseram a tratar do trabalho feminino nas fábricas no início do capitalismo fabril brasileiro e mineiro. Como exem-

3 HOBSBAWM, E. J. Da revolução industrial inglesa ao imperialismo. Rio de Janeiro: Forense-Universitária, 1979, p.64.

4 FOOT, Francisco e LEORNARDI, Victor. História da indústria e do trabalho no Brasil: das origens aos anos vinte. São Paulo: Global Editora, 1982, p.183. (Col. Teses)

5 LIBBY, Douglas Cole. Transformação e trabalho em uma economia escravista: Minas Gerais no século XIX. São Paulo: Brasiliense, 1988, p.233-235.

6 MAGALHÃES. Cristiane Maria. Mundos do capital e do trabalho: a construção da paisagem fabril itabirana (18741930). Belo Horizonte: Universidade Federal de Minas Gerais, 2006, p.77. (História, Dissertação de mestrado).

7 Discurso proferido por Antônio Gonçalves Chaves à Assembléia Legislativa Provincial de Minas Gerais em 2 de agosto de 1883. Ouro Preto, Tipografia do Liberal Mineiro, 1883. Disponível em http://brazil.crl.edu/bsd/bsd/490/ index.html. 
plo, podemos citar: Maragareth Rago ${ }^{8}$, Concessa Vaz de Macedo, ${ }^{9}$ Maria Valéria Juno Pena, ${ }^{10}$ Domingos Giroletti1 ${ }^{11}$ e Douglas Cole Libby, ${ }^{12}$ os dois últimos mais voltados para o processo de industrialização no contexto da economia mineira, do que necessariamente para o trabalho feminino. De qualquer forma, reservadas as diferentes abordagens adotadas por cada um desses autores, as análises que desenvolveram representam um valioso arcabouço de conhecimentos acerca das condições de trabalho das mulheres nas fábricas têxteis, do papel do trabalho feminino na dinâmica da produção capitalista, e mesmo de algumas questões de ordem cultural que incidiram na inserção e no trabalho das mulheres nas fábricas, como é o caso de Margareth Rago.

Se por um lado contemplamos aqui um tema que poderia ser considerado como já apreciado. Por outro, consideramos que ele ganha pertinência, pois vem acrescido da tentativa de alcançar as mulheres no cotidiano das fábricas mineiras, dando visibilidade à sua vida, às relações nas quais estavam inseridas, às questões que envolvem a opção da fábrica pela sua mão-de-obra. Buscamos discutir, igualmente, que mulher é essa que se inseriu nas fábricas e como a fábrica se constituiu como mais um espaço de formação e conformação de um tipo ideal de mulher defendido na época. ${ }^{13}$

\section{O negócio das fábricas: a Companhia de Fiação e Tecidos Cedro e Cachoeira e a industrialização em Minas Gerais}

Stanley J. Stein, ${ }^{14}$ analisando o surgimento da indústria têxtil no Brasil, argumentava que para muitos "a indústria democrática apontava o caminho da modernização e revitalização do Brasil. Só ela, pensavam alguns brasileiros, poderia trazer felicidade para o trabalhador e aumentar o capital dos investidores". Estas palavras citadas por Stein parecem encontrar eco em Bernardo Mascarenhas, importante industrial mineiro e um republicano convicto, o idealizador e um dos fundadores da Fábrica do Cedro, a primeira fábrica de tecidos que deu origem à CCC, que assim se referia à indústria, no final do século XIX:

8 RAGO, Margareth. Do cabaré ao lar: A utopia da cidade disciplinar - Brasil 1890-1930. Rio de Janeiro: Paz e Terra, 1985.

9 MACEDO, Concessa Vaz. Diferenciação ocupacional e salarial do operariado feminino "vis-a-vis" o masculino na indústria brasileira, 1985. Belo Horizonte: CEDEPLAR, Universidade Federal de Minas Gerais, 1985. (Economia, Dissertação de mestrado).

10 PENA, Maria Valéria Junho. Mulheres e trabalhadoras: presença feminina na constituição do sistema fabril. Rio de Janeiro: Paz e Terra, 1981.

11 GIROLETTI, Domingos. Fábrica, convento e disciplina. Belo Horizonte: Imprensa Oficial: 1991

12 LIBBY, Douglas Cole. Transformação e trabalho em uma economia escravista.

13 As ideias aqui apresentadas resultam de uma pesquisa realizada pela autora na Companhia de Fiação e Tecidos Cedro e Cachoeira - CCC em seus primeiros anos de funcionamento, LIMA, Junia de Souza: De meninas fiandeiras a mulheres operárias: a inserção da mão-de-obra feminina na Companhia de Fiação e Tecidos Cedro e Cachoeira - 1872-1930. Belo Horizonte: Tecnológica do CEFET/MG, 2009. (Educação, Tese de mestrado).

14 STEIN, Stanley J. Origens e evolução da indústria têxtil no Brasil. Rio de Janeiro: Campus, 1979, p.97. 
Se a nossa Província tivesse umas 20 fábricas bem colocadas, por certo que estaria em condições mais vantajosas nas suas finanças e progresso, pois os milhões de metros de fazenda que fossem fabricados seriam consumidos na Província, lançando fora dos mercados as ordinárias drogas européias, e assim deixar-se-ia de exportar bons milhares de contos por ano, que, ficando na Província, dariam grande impulso à lavoura e ao comércio, e à indústria, tríplice base que faz a grandeza, o progresso e a independência das nações. ${ }^{15}$

De fato, mesmo tendo seus primeiros contornos delineados ainda no início do século XIX, foi a partir da década de 1870 que o processo de industrialização no Brasil se expandiu e se fortaleceu impulsionado principalmente pelo algodão. A partir desse período, muitas fábricas de tecidos foram criadas e muitas já instaladas conseguiram ampliar seu capital e sua produção. Os ares republicanos já começavam a soprar e fortalecida, a indústria têxtil se inseriu no período como o próprio símbolo da modernidade e do progresso. E nada melhor que as fábricas com suas chaminés enfumaçadas para simbolizar esse ideário.

Sem dúvida, a industrialização significou o caminho para aproximar o Brasil do modelo capitalista da Europa e dos Estados Unidos. Segundo Domingos Giroletti ${ }^{16}$ buscava-se formar nos operários "um novo estilo de vida, uma nova ética e uma nova sexualidade que se contrapusessem à sistemática de viver do trabalhador escravo, camponês ou artesão." E ainda segundo esse autor a fábrica, por meio de suas ações: disciplinar, técnica e ideológica, constituiu-se como a instância formadora dessa nova mentalidade, denominada por ele como uma nova "cosmovisão".

Em Minas Gerais, esses ares de progresso e modernidade começaram a soprar ainda na primeira metade do século XIX com as primeiras iniciativas de instalação na província de uma fábrica de tecidos. Em 1838 por iniciativa de Antônio Luiz d'Avelar foi fundada a Companhia Mineira Industrial e por volta de 1850 uma segunda fábrica denominada de Cana do Reino foi fundada por dois ingleses, Pigot e Cumberland. Estes dois empreendimentos não foram adiante devido a problemas financeiros, administrativos e mesmo por falta de mão-de-obra capacitada. Libby, ${ }^{17}$ referindo-se à Cana do Reino afirma que foi uma fábrica mal administrada e, "nunca passou de uma pequena filatória que contratava a tecelagem por fora, aproveitando a indústria doméstica já existente" e complementa "ao longo de sua agoniada existência, a Cana do Reino fora um fiasco e quase uma falsa indústria". Tudo indica que esta fábrica encerrou definitivamente suas atividades no início da década de 1870.

15 Apud: MASCARENHAS, Nelson Laje. Bernardo Mascarenhas: o surto industrial em Minas Gerais. Rio de Janeiro: Gráfica e Editora Aurora LTDA. 1954, p.56.

16 GIROLETTI, Domingos. Fábrica, convento e disciplina. Belo Horizonte: Imprensa Oficial, 1991, p.19.

17 LIBBY, Douglas Cole. Transformação e trabalho em uma economia escravista, p.224. 
Mas em 1872, este cenário começou a mudar. É neste período que têm início as atividades da CCC. A sua história se insere num período significativo de expansão da indústria têxtil fabril nacional. Esta ampliação, de acordo com Ricardo Zimbrão Affonso de Paula,$^{18}$ se deu pela junção de diversos fatores como a expansão monetária ocorrida durante a Guerra do Paraguai, a manutenção das tarifas de importação combinadas com uma valorização cambial, colocadas em prática logo depois da guerra e a retração das exportações brasileiras do algodão devido o retorno da produção desta cultura agrícola por parte dos Estados Unidos, favorecida pelo fim da Guerra Civil naquele país. Este processo acarretou um aumento das reservas internas de matéria-prima têxtil que, com preços baixos, atraiu mais investimentos na área. Houve verdadeiramente uma "epidemia de fábricas" resultante do boom expansionista iniciado neste período.

Tal expansão não passou despercebida entre os fundadores da CCC, e foi assim descrita por Caetano Mascarenhas por meio de uma carta escrita em 11 de novembro de 1886 cujo destinatário era o seu irmão, gerente da Fábrica do Cedro:

Diga como vai isso por ahi (sic). Já deveis saber que o José João formou Companhia para assentar uma fábrica de tecidos na freguesia do Pau Grosso, e me parece que já há por lá subscritos 150:000.000 (sic) e tratam de tirar aguada da fazenda de São Vicente. Assentamento de máquinas é epidemia por agora. ${ }^{19}$

A sociedade Mascarenhas \& Irmãos foi fundada em 1868, pelos irmãos Antônio Cândido, Bernardo e Caetano Mascarenhas com a finalidade de instalar uma fábrica de tecidos. Depois de organizar o capital, escolher o lugar, comprar e instalar as máquinas e fazer as primeiras contratações de operários os três irmãos conseguem pôr em funcionamento a Fábrica do Cedro no dia 12 de agosto de 1872, localizada no Povoado do Cedro,20 pertencente ao Arraial de Tabuleiro Grande, Freguesia de Sete Lagoas.

Foi a pioneira no setor têxtil em Minas Gerais, se aventurando numa atividade que não despertava confiança aos fazendeiros e comerciantes mineiros, principalmente depois do fracasso da fábrica Cana do Reino. Acrescido a isso, foi instalada numa região rural, afastada de tudo, com escassez de mão-de-obra qualificada, já que a maioria da população vinha de atividades agrícolas ou comerciais. E ainda sem infra-estrutura de estradas que facilitassem o transporte de produtos, maquinários, matérias-prima e outros produtos do gênero. Isso sem mencionar o desafio de enfrentar

18 PAULA, Ricardo Zimbrão Affonso de E. Do caminho novo das Minas dos Matos Gerais emerge a 'Manchester Mineira' que se transformou num "baú de osso"- História de Juiz de Fora: da vanguarda de Minas Gerais à "industrialização periférica", Campinas, UNICAMP, 2006, p.161. (Economia, Tese de doutorado).

19 Caetanópolis. Museu Têxtil Décio Magalhães Mascarenhas, (MTDMM) Caixa de correspondência n.11.

20 O povoado do cedro se emancipou na década de 1950 e atualmente é a cidade de Caetanópolis. 
a concorrência dos produtos estrangeiros, que já tinham um mercado consumidor cativo, principalmente nas áreas urbanas mais desenvolvidas.

Regina Horta Duarte ${ }^{21}$ descreve o povoado do Cedro como um lugarejo pequeno, de baixa densidade demográfica onde predominavam as atividades agro-pecuárias pouco desenvolvidas e com mecanização precária. Tratava-se de uma região pobre cujo domínio político era exercido pela Família Mascarenhas, proprietários de grande extensão de terra e, agora, de fábrica de tecidos.

O impacto que a Fábrica do Cedro causou na economia local foi grande, gerou um número considerável de novos empregos, trouxe dinheiro para a região, novos recursos e, com estes, estradas e infra-estrutura para a localidade. ${ }^{22}$ A euforia causada por tal empreendimento levou Nelson Senna ${ }^{23} \mathrm{em}$ 1913 a comparar a Villa de Paraopeba, antiga Tabuleiro Grande, às cidades de Manchester, na Inglaterra e Lowell, nos Estados Unidos. Segundo ele:

O Município de Villa de Paraopeba (...) é dos distritos mais industriosos de Minas e do Brasil inteiro. Nele formiga uma legião de operários, como se fosse uma região de manufaturas de panos, como Manchester, na Inglaterra, ou como Lowell, nos Estados Unidos da América do Norte. ${ }^{24}$

Instalada inicialmente com 18 teares adquiridos nos Estado Unidos, acionados por uma roda d'água de 40 cavalos de potência, ${ }^{25}$ a Fábrica do Cedro prosperou e um ano mais tarde, já havia atingido sua plena capacidade produtiva e novas máquinas já estavam encomendadas. ${ }^{26}$ Cerca de três anos após a sua inauguração, o engenheiro inglês James Wells de passagem pelo povoado do Cedro fez o seguinte relato sobre as condições da fábrica:

Pela manhã levantamos cedo e fomos visitar a fábrica, que recebe o algodão bruto, sem beneficiamento, trazido à porta pelos lavradores que fazem plantações nas adjacências do Rio das Velhas. Esse algodão é descaroçado, fiado e depois tecido em panos de duas qualidades, sendo a melhor usada para a confecção de camisas e calças grosseiras, e a inferior usada na fabricação de sacos. Havia em trabalho 18 teares que, com o resto do maquinismo, eram acionados por uma superpotente roda de água de 50 pés, solidamente construída. Em tudo imperava um método e uma ordem perfeitos. $\mathrm{O}$ barulho das máquinas e a excelente disciplina mantida nos compartimentos de trabalho eram outra cena

21 DUARTE, Regina Horta. O povoado do Cedro: um palco, muitas histórias. Revista do Departamento de História, Belo Horizonte/UFMG, v.1, n.2, p.102-120, junho de 1986.

22 DUARTE, Regina Horta. O povoado do Cedro: um palco, muitas histórias, p.102-120.

23 Arquivo Público Mineiro. SENNA, Nelson. Anuário de Minas Gerais, 1913. [S.I.: s.n].

24 SENNA, Nelson. Anuário de Minas Gerais, 1913, p.595.

25 GIROLETTI, Domingos. Fábrica, convento e disciplina, p.24

26 VAZ, Alisson Mascarenhas. Cia. Cedro e Cachoeira: história de uma empresa familiar - 1883-1987. Belo Horizonte: Cia. de Fiação e Tecidos Cedro e Cachoeira, 1990, p.71. 
inédita que encontramos no interior de Minas. A fábrica havia sido montada há cerca de três anos, e dera tanto lucro que já estava quase inteiramente paga. ${ }^{27}$

Tal prosperidade acabou influenciando outros membros da família a se arriscarem no negócio das fábricas. Em 1873 foi criada outra sociedade visando à instalação de uma nova fabrica de tecidos, composta por três irmãos e um cunhado, a Sociedade Mascarenhas Irmãos \& Barbosa, que mais tarde passou a se chamar Mascarenhas \& Barbosa. A nova fábrica foi inaugurada em janeiro de 1877 na região de Curvelo e recebeu o nome de Fábrica da Cachoeira. Maior do que a Fábrica do Cedro, possuía inicialmente 52 teares, quase o triplo da quantidade instalada na Fábrica do Cedro. ${ }^{28}$

A fusão da Fábrica do Cedro e da Cachoeira em uma única companhia ocorreu em 1883. Isso se deu em decorrência do aumento da concorrência, principalmente, ocasionada pelo surgimento de outras fábricas de tecidos na região. Nas palavras de Mascarenhas:

Sob qualquer ângulo que encarassem o assunto, chegavam sempre à mesma conclusão: colocadas as duas forças sob uma única orientação, a crescente concorrência poderia ser enfrentada com mais facilidade e maior desenvolvimento seria conseguido e em menos tempo. ${ }^{29}$

Girolettijo acrescenta que a visão modernista de Bernardo Mascarenhas também contribuiu para a fusão das duas fábricas em uma única companhia, pois "constatara na Europa e nos Estados Unidos o movimento de concentração de capital formando grandes empresas". Conforme esclarece o próprio Bernardo Mascarenhas em carta enviada aos irmãos durante o processo de negociação para a criação da CCC:

Denominei a companhia - Cedro \& Cachoeira -, de preferência ao nome que de lá veio - União Industrial; já as nossas firmas muito conhecidas e acreditadas em toda a Província desaparecem perante a organização da nova sociedade. Acho justo, pois, que se conservem os nomes das duas fábricas que fundamos e que são também muito conhecidas. Espero que a semente que lancei há 8 anos brevemente dará frutos com que sonhei desde 1874 quando extasiava-me diante dos altaneiros estabelecimentos manejados por poderosas companhias inglesas. Se as minhas idéias fossem postas em prática quando iniciei a idéia da fusão, que encontrou alguma indiferença e obstáculos próprios daqueles

27 MASCARENHAS, Geraldo Magalhães. Centenário da fábrica do Cedro: 1872-1972. Belo Horizonte: Cia. de Fiação e Tecidos Cedro e Cachoeira, 1972, p.85.

28 GIROLETTI, Domingos. Fábrica, convento e disciplina, p.28; MASCARENHAS, Geraldo Magalhães. Centenário da fábrica do Cedro: 1872-1972. Belo Horizonte: Cia. de Fiação e Tecidos Cedro e Cachoeira, 1972, p.103; VAZ, Alisson Mascarenhas. Cia. Cedro e Cachoeira: história de uma empresa familiar - 1883-1987, p.75.

29 MASCARENHAS, Geraldo Magalhães. Centenário da fábrica do Cedro, p.109.

30 GIROLETTI, Domingos. Fábrica, convento e disciplina, p.28. 
tempos, outro galo nos cantava, - já estaríamos 4 ou 6 anos adiante. Contudo, a árvore plantada não morreu e brevemente espero ver-lhe os abençoados frutos. ${ }^{31}$

Um ano antes da criação da Cia "Cedro \& Cachoeira", Bernardo iniciou a montagem de uma fábrica de tecidos na fazenda São Sebastião, de propriedade de seu pai, o Major Antônio Gonçalves da Silva Mascarenhas. A fábrica de São Sebastião, como ficou conhecida, foi registrada em nome da matriarca da família, D. Policena da Silva Mascarenhas. O diferencial dessa fábrica era a condição social dos seus trabalhadores, cuja maioria se compunha de escravos. ${ }^{32} \mathrm{~A}$ Fábrica de São Sebastião não foi incorporada a CCC, segundo o contrato ${ }^{33}$ firmado com a CCC, esta se comprometia a comprar toda a produção de tecidos da fábrica.

Em 1891 a CCC ampliou seu capital com a aquisição da Fábrica de São Vicente, localizada na região de Baldim. Esta fábrica foi adquirida no final de 1891, mas só entrou em funcionamento em 1893, devido a problemas de falta de água suficiente para mover o equipamento, a sua má localização e as péssimas condições de salubridade. ${ }^{34}$

Atualmente a Cia de Fiação e Tecidos Cedro e Cachoeira compreende quatro fábricas em Minas Gerais, a fábrica do Cedro, a pioneira, localizada em Caetanópolis, antigo povoado do Cedro; as fábricas Victor Mascarenhas e Caetano Mascarenhas, ambas localizadas em Pirapora e a fábrica Geraldo Magalhães Mascarenhas, localizada no município de Sete Lagoas.

No que se refere à mão-de-obra, esta era composta por uns poucos técnicos ingleses e os trabalhadores nacionais, que se dividiam entre aqueles que executavam tarefas consideradas mais qualificadas como os ferreiros, os chefes de seção, marceneiros, etc e a grande maioria composta homens, mulheres e crianças considerados como desqualificados. Segundo Domingos Giroletti35 trava-se de uma "massa de trabalhadores" recrutada na região e que se encarregava das mais diversas tarefas dentro das fábricas. E seguindo a tendência de fábricas capitalistas instadas tanto no Brasil quanto no exterior as primeiras fábricas da CCC foram se tornando o grupo mais significativo dessa massa operaria.

De acordo com os registros anotados no primeiro livro de ponto da Fábrica do Cedro datado de 1873 a 1878, havia na primeira semana de janeiro de 1873, 19 operários registrados, dos quais 4 eram mulheres. Porém com o passar do tempo esse número foi se alterando. Em março de 1886, 60\% dos trabalhadores na Fábrica do Cedro eram de mulheres. Esta

31 MASCARENHAS, Nelson Lage. Bernardo Mascarenhas: o surto industrial em Minas Gerais. Rio de Janeiro: Gráfica Editora Aurora, 1954, p.71.

32 LIBBY, Douglas C. Transformação e trabalho em uma economia escravista, p.299.

33 MTDMM. Cx. Box n.13A.

34 MASCARENHAS, Geraldo Magalhães. Centenário da fábrica do Cedro, p.155

35 GIROLETTI, Domingos. Fábrica, convento e disciplina. 
preponderância feminina no conjunto de trabalhadores permaneceu, pelo menos até dezembro de 1940, quando havia na Fábrica do Cedro, cerca de 383 operários dos quais 199 eram do sexo feminino. ${ }^{36}$ Tratar um pouco da vida dessas operárias dentro das fábricas da CCC, da sua condição social e de seus dilemas é a nossa principal tarefa.

\section{Matizes de um retrato: quem eram as operárias e de onde vinham}

Em 06 de janeiro de 1898 o gerente da fábrica de São Vicente escreve uma carta endereçada ao superintendente da CCC, informando a este sobre a abadessa escolhida para reger um dos conventos da Cia, vejamos o que ele diz em sua missiva:

A abadessa arranjada é boa. É só mandares condução para ela, uma moça, duas meninas taludas e um rapaz. Fiz-lhe ver que não querias lá o rapaz, para não ter desculpas de visitar a mãe e irmãs no Convento, ela se sujeita a separar-se dele uma vez que lhe dês emprego e. É rapaz sério e incapaz de qualquer má ação. Boa família. (...) Não tratei preço com a abadessa. É gente de boa raça e muito pobres e satisfazem-se com qualquer coisa justa e razoável. Manda buscá-los. ${ }^{37}$

Esta e outras inúmeras cartas escritas pelos gerentes da Cia e trocadas em sua rede de correspondentes nos ajudam a delinear um retrato das operárias, da sua condição social, bem como das condições impostas e vividas por essas mulheres no cotidiano das fábricas aqui analisadas. No caso da carta acima podemos inferir que se trata de uma mulher, talvez mais velha e viúva, pois vem sem o marido e traz consigo os quatro filhos que também podem se empregar nas fábricas. Além disso, o autor da missiva deixa bem claro que se trata de uma família muito pobre, e que por isso mesmo se sujeita a qualquer coisa que lhe for oferecida.

Ainda com base na correspondência, podemos ver que a operária esta sendo contratada para ser a abadessa do convento e neste caso não poderá levar o rapaz para morar consigo nesse ambiente. Aqui podemos ver as condições impostas a ela e a sua família em troca do trabalho, ou seja, a separação entre seus membros, o isolamento da mãe e das filhas no convento e um salário pelos serviços o qual o gerente considere justo pagar.

O caso da abadessa referido na carta acima ilustra de forma valiosa a situação e a condição das operárias. Tratava-se de um conjunto de mulheres composto por meninas, moças mais jovens, mulheres adultas. Algumas eram órfãs, outras solteiras e muitas eram viúvas. Trabalhadoras em sua maioria migrantes que eram contratadas em localidades distantes das fábricas. E a maioria delas, fossem solteiras, órfãs ou viúvas, deveriam vir sós,

36 MTDMM. Livro de ponto da Fábrica do Cedro de outubro de 1940 à agosto de 1941.

37 MTDMM. Caixa de correspondência n.10A. 
ou seja, desacompanhadas de qualquer membro da família, a menos que pudessem, do mesmo modo, serem empregados nos serviços das fábricas. Evitava-se a todo custo, a contratação de mulheres casadas. Várias são as missivas que dão conta desta preferência dos industriais, como o trecho transcrito abaixo, cuja carta de autoria do gerente da Fábrica do Cedro estava endereçada ao gerente da Fábrica de Montes Claros: "receberei como disse a v.s. vinte moças para o Convento, mas sós, sem ligações com suas famílias, pois para estas não tenho absolutamente cômodos". 38

Esta opção por mulheres "sozinhas" impôs às fábricas a necessidade de organizar a acomodação para as mesmas. No caso das viúvas que vinham com filhos ou outros parentes e "agregados" eram reservadas casas na vila operária. Já para as solteiras, as órfãs e as viúvas sós foram organizados os conventos. Denominado por Michelle Perrot ${ }^{39}$ como "convento de fábrica", estas verdadeiras instituições criadas dentro das fábricas caracterizavamse pela rigidez na disciplina, pelo controle sobre a vida cotidiana das suas moradoras e pelo isolamento imposto às mulheres. A regente, mesmo sendo leiga, recebia o nome de "abadessa" e sua principal função era manter sob controle as operárias. Como bem descreveu o gerente da Fábrica do Cedro em uma missiva de 17 de agosto de 1889:

A fábrica sustenta aqui um convento onde são recolhidas moças operárias, regidas por uma senhora de excelentes qualidades e de toda confiança, sob cujas vistas vivem as moças satisfeitas, em comunidade, passeando, indo à missa no arraial, que é próximo; tem médico, o botico por conta da fábrica, e só provêem de comestíveis e vestuário; as despesas de alimentação tornam-se medíocre para cada uma, visto como é repartida entre todas, sendo a casinha uma só; assim quanto maior for o número, mais favorável se tornará a despesa de cada uma. O Convento é sujeito a gerência geral. ${ }^{40}$

Domingos Giroletti ${ }^{41}$ pondera que se tratava de uma instituição importante para os proprietários, que se encarregavam pessoalmente da sua organização, da contratação da abadessa e acompanhavam de perto o seu dia-a-dia. Segundo Evélyne Surellot ${ }^{42}$ esses "pensionatos" para moças operárias simbolizavam uma "mistura de moralismo puritano e de avidez capitalista", que corporificavam a ordem "com toda sua tenaz hipocrisia", e em alguns casos com as "cores do catolicismo".

Contudo esses conventos de fábrica, mesmo não sendo católicos, guardavam algumas semelhanças com os religiosos, pois eram lugar de reclusão, vigilância, obediência e controle exacerbado, além de reproduzi-

38 MTDMM. Livro Copiador de Cartas da Fábrica do Cedro, 1888-1889, p.419-420.

39 PERROT, Michelle. As mulheres ou o silêncio da história. Bauru, SP: EDUSC, 2005

40 MTDMM. Livro Copiador de Cartas Fábrica do Cedro, 1888-1889, p.419-20.

41 GIROLETTI, Domingos. Fábrica, convento e disciplina.

42 SURELLOT, Évelyne. A mulher no trabalho. Rio de Janeiro: Editora Expressão e Cultura, 1970, p.86. 
rem rituais como as rezas e as novenas. Ademais algumas cartas analisadas sugerem que a presença física de representantes da Igreja era algo comum nesses estabelecimentos, como fica claro no trecho da carta do gerente da Fábrica de São Vicente dando noticias sobre o convento que acabara de ser organizado nesta fábrica: "Vai o José Nunes para trazer d. Joaquinha, pois o convento está pronto e já com algumas freiras". ${ }^{43}$ Mas é importante ressaltar que apesar dessa aproximação ao modelo de convento católico, as operárias não realizavam os votos religiosos e não havia a proibição de namoros e casamentos, despeito de toda a vigilância que tais fatos suscitavam por parte dos gerentes e da abadessa.

A leitura mais atenta de toda a correspondência analisada revela algumas facetas da relação de trabalho vivenciadas pelas mulheres e dão pistas de vantagens oferecidas pela mão-de-obra feminina. As despesas ali eram diminutas e de responsabilidade das próprias operárias. Era delas o encargo de conseguir alimentação, vestuário e manter limpo todo o ambiente. Para os industriais, isto barateava o valor da mão-de-obra, pois se responsabilizavam apenas pela construção da edificação, o fornecimento de utensílios básicos como camas, panelas, talheres e outros necessários para o dia-a-dia. Mesmo assim estes utensílios muitas vezes deveriam ser compartilhados entre as operárias e as condições de acomodação eram precárias. Ademais acomodar operárias em conventos, diminuía os gastos com a construção de moradias para grupos familiares nas vilas operárias.

Além de todo benefício econômico, os conventos facilitavam a vigilância e o controle sobre as operárias. Uma vigilância interna exercida pela abadessa e outra externa, realizada pelos próprios gerentes.

De todo modo considera-se aqui que a escolha de mulheres "sozinhas" e a organização de conventos inspirados no modelo de conventos católicos para abrigar parte delas, especialmente as meninas e as jovens solteiras é algo emblemático, nesse "emaranhado" no qual as mulheres estavam inseridas. Arrisca-se a dizer que eles são o símbolo maior de um traço patriarcal e cultural que entremeava as relações de gênero no período histórico em questão, que acabou sendo incorporado nas relações entre patrões e empregadas nas fábricas têxteis aqui analisadas.

Sozinhas, sem marido, longe dos pais, padrinhos ou outra figura masculina que pudessem ampará-las, nada mais adequado do que um convento. Haja vista que, no período em questão, esta instituição simbolizava o lugar quase sagrado de reclusão e proteção das mulheres, principalmente as sozinhas, ou seja, sem qualquer individuo do sexo masculino capaz de vigiá-las, controlá-las e protegê-las. Tânia Quintaneiro ${ }^{44}$ analisando estas

43 MTDMM. Caixa de correspondência n.3, datada de 31 de outubro de 1893.

44 QUINTANEIRO, Tânia. Retratos do Brasil: o cotidiano feminino no Brasil sob o olhar dos viageiros do século XIX. Petrópolis: Vozes, 1995, p.59. 
instituições pondera que a sua principal utilidade era a guarda de senhoritas e de senhoras que ali viviam seguras e resguardadas.

Sendo assim os gerentes e proprietários da CCC tomaram para si a tarefa de zelar, cuidar e proteger a honra, a virtude e a integridade de suas jovens operárias. Da mesma forma como deveria fazer qualquer figura masculina na vida dessas mulheres. Tarefa essa legitimada, de alguma forma, pela sociedade local, conforme explicitado por um comerciante que buscava um lugar seguro onde colocar a sobrinha órfã: "Tenho uma sobrinha órfã de pai e mãe, a qual acha-se (sic) em meu poder, e peço-lhe a sua valiosa proteção arranjando-me um lugar para ela no Convento e bem assim um emprego na fábrica". ${ }^{45} \mathrm{Ou}$ em outra escrita pelo gerente da Fábrica da Cachoeira, em 30 de agosto de 1900, envolvendo um tintureiro da fábrica e uma operária:

Tem esta por motivo principal avisar-te que devido ao incorreto comportamento do tintureiro (...), o qual procurou seduzir neste local uma empregada, moça de família, o que ficou automaticamente comprovado por uma carta escrita pelo próprio punho do mesmo à mesma moça, despachei-o hoje deste estabelecimento (...). O tal tintureiro é uma droga das mais ordinárias, seduziu e mandou raptar uma mocinha ingênua; e para exemplo e moralidade do lugar vou processá-lo, assinando como parte no processo. ${ }^{46}$

Michelle Perrot ${ }^{47}$ chama a atenção para o fato de que os proprietários de fábricas, ao lançarem mão das mulheres sozinhas, acabavam mostrando-se preocupados em preservar a família, já que ainda segundo essa mesma autora, a mulher casada "não pertence mais a si mesma, ela pertence a seu marido e a seus filhos; reunidos eles formam a família". Uma carta escrita por Mascarenhas e Irmãos (proprietários da Fábrica do Cedro), endereçada à operária Hermenegilda Mitz, em 05 de fevereiro de 1881, corrobora o com o que foi dito:

\begin{abstract}
O trabalho é a lei suprema da humanidade e a preguiça é cancro roedor, causa da miséria e que muitos prejuízos têm dado a esta fábrica. Nos nove anos que Vmcê. tem trabalhado aqui, tem desenvolvido sempre uma atividade de dedicação tão acima do comum que raras têm sido as companheiras que lhe têm igualado. Se seu trabalho nos tem sido lucrativo, seu exemplo muito mais vantajoso nos tem sido. É, portanto, nosso dever, hoje, no dia do seu casamento, manifestar-lhe o quanto Ihe somos gratos, pedindo-lhe haja de aceitar o pequeno adjutório, que incluso Ihe oferecemos. Que Deus abençoe o seu consórcio são os votos dos respeitadores e obrigados, Mascarenhas e Irmãos. ${ }^{48}$
\end{abstract}

45 MTDMM. Caixa de correspondência Box n.1, datada de 22 de julho de1890.

46 MTDMM. Caixa de correspondência Box n.30A.

47 PERROT, Michelle. As mulheres ou o silêncio da história.

48 MTDMM. Livro Copiador de Cartas da Fábrica do Cedro de 1881 a 1883, p.486. 
Que exemplo a operária Hermenegilda Mitz foi capaz de ser que lhe fez merecedora de uma carta tão grata e porque não terna? Consideramos que a operária foi capaz de corresponder ao que se esperava dela, trabalhou com o afinco e a dedicação, sendo obediente, contida e de comportamento moral ilibado, atitudes esperadas das mulheres e que as fábricas valorizavam também em suas operárias. Outra correspondência encaminhada pelo gerente da Fábrica de São Vicente ao gerente da Fábrica do Cedro reforça a importância do bom comportamento das mulheres para o emprego nas fábricas: "Estou hoje despachando para lá 2 famílias de operários daqui e mais 19 raparigas, bem comportadas e boas que de certo nos prestarão bons serviços". ${ }^{49}$

O que se depreende de tudo isso é a existência de um processo que fez das fábricas têxteis aqui consideradas uma instituição formativa e educativa das mulheres. Grande parte das trabalhadoras passava cerca de 30 a 40 anos no serviço fabril, elas cresciam e tornavam-se adultas nesses locais e, desta forma, o seu aprendizado para o trabalho passava também por um caminho "tortuoso" de aprenderem a ser mulheres a partir de um modelo simbólico considerado importante para os seus patrões. Modelo esse que talvez não seja o das operárias, mas que serve para aproximar as fábricas à escola, à família e à religião, cada qual à sua maneira, que igualmente, se encarregaram de educar e formar as mulheres

Ao buscar formas de isolar, controlar, vigiar e proteger as "suas" operárias, as fábricas de tecidos acabaram por transpor para o espaço público um modelo de relação já consolidado no espaço privado. Mesmo inserida na esfera pública do trabalho, as mulheres se debatiam com um processo de disciplinarização e de relações que insistia em mantê-las na ordem do privado, da qual o convento pode ser considerado o símbolo mais representativo. Conforme explica Margareth Rago trata-se de uma relação pedagógica descrita por ela como:

Paternalista, de subordinação da mulher frente ao homem, exatamente como no interior do espaço doméstico. O pai, o marido, o líder devem ser obedecidos e respeitados pelas mulheres, incapazes de assumirem a direção de suas vidas individuais ou enquanto grupo social oprimido. ${ }^{50}$

E como ficam as trabalhadoras em meio a tudo isso? Mesmo reconhecendo o poder, o domínio e a ordem impostos a elas, as operárias encontravam maneiras de burlar este sistema. Com movimentos até certo ponto criativos e aproveitando as oportunidades surgidas criaram táticas que as ajudaram, vez por outra, a esquivar-se. Nesse sentido há que se destacarem

49 MTDMM. Caixa de correspondência n.5 datada de 24 de outubro de 1893.

50 RAGO, Margareth. Do cabaré ao lar, p.67-68 
os namoros escondidos, as escapulidas e o abandono dos conventos, as uniões ilegítimas, a oposição em engajarem-se no trabalho fabril, as reações diretas que aconteciam esporadicamente contra a hierarquia das fábricas e tantos outros casos narrados pelos gerentes na correspondência produzida por eles. Tudo isso nos faz lembrar a observação de Michelle Perrot: "as mulheres não são nem passivas, nem submissas. A miséria, a opressão, a dominação, por mais reais que sejam não bastam para contar sua história". ${ }^{51}$

Entretanto diante das condições sociais, culturais e econômicas que diziam respeito às mulheres do período, especialmente a parcela pobre e desvalida, o trabalho nas fábricas e tudo o que poderia trazer acabou se tornando um "mal necessário". Talvez uma alternativa possível à prostituição e ao descaminho, perigos reais que rondavam muitas mulheres nessa condição, no período histórico aqui recortado. ${ }^{52}$ Desta forma a despeito das condições de trabalho, consideradas hoje aviltantes, a possibilidade de trabalho, moradia e proteção oferecidos pela CCC era algo que muitas não podiam recusar.

\section{"Às mulheres: os fios, os tecidos e as máquinas simples"}

A epígrafe deste artigo é uma carta datada de 23 de fevereiro de 1887, escrita pelo gerente da Fábrica da Cachoeira endereçada ao superintendente da CCC na qual ponderava sobre os benefícios de se empregar trabalhadoras do sexo feminino nos serviços da Cia, dizia ele: "como sabes não convém que façamos mais casas; as que têm são suficientes, tanto mais que na proporção que alguma família se retira, a vou substituindo por moças do convento que são os melhores empregados". ${ }^{53}$

De fato, analisando essa missiva, além de outras cartas e alguns documentos como os livros de ponto de empregados e os dossiês de alguns trabalhadores verificamos que as mulheres eram as mais constantes e assíduas. A média de anos que se dedicavam ao trabalho nas fábricas era de 35 a 40 anos, enquanto a dos trabalhadores masculinos ficava em torno dos 25 a 30 anos de serviço. Acrescido a isso, trabalhavam por produção, recebendo uma diária bem menor que a de seus colegas masculinos e, quando moradoras dos conventos, encarregavam-se do próprio sustento. Ademais, como já foi dito, dada a fragilidade social e econômica em que se encontravam, a necessidade de trabalho era grande e, assim, ao que parece, submeteram-se melhor à dominação, ao controle e à vigilância patronal e masculina imposta a elas no cotidiano do trabalho. Assim sendo foram se tornando aos olhos dos patrões "nos melhores empregados".

51 PERROT, Michelle. As mulheres ou o silêncio da história, p.152.

52 Sobre isso sugerimos a leitura de RAGO, Margareth. Do cabaré ao lar.

53 MTDMM. Carta do gerente da Fábrica da Cachoeira, datada de 23 de fevereiro de 1887, Caixa Box n.4. 
No entanto, o trabalho feminino impôs aos industriais um desafio, qual seja o de torná-las operárias práticas e boas para a produção têxtil, capaz de manusear as máquinas com desenvoltura e diligência, produzindo grandes quantidades de tecidos e com a qualidade esperada. Diversas cartas trocadas entre os gerentes das fábricas da CCC trazem valiosos registros desse processo. Em uma delas, datada de 16 de julho de 1897, o gerente da Fábrica de São Vicente não deixava dúvidas quanto à dificuldade de formar as boas tecelãs:

Me parece impossível mandar-te as 12 tecelonas das melhores que tem em S. Vicente, conforme pedes. (...) Conhece que nos tempos atuais não é tão fácil se arranjar isso, e deves entender que não é sem muito trabalho que isto tenho arranjado. Atualmente tenho 67 teares trabalhando com pessoal todo ainda atrasado, e não dando por essa razão uma produção agradável; como, pois hei de mandar-te as melhores tecelonas? Algumas tecelonas tocam a dois teares. ${ }^{54}$

A importância de boas tecelãs fica ressaltada em outra carta escrita pelo mesmo gerente acima: "Esta semana a fábrica tem trabalhado muito bem com 34 teares, e se as tecelonas fossem práticas todas, faria muito pano". 55 O que estas e outras epístolas analisadas sinalizam é que o processo de aprendizagem das operárias se dava no trabalho e pelo trabalho. Era na lida diária com a máquina e no aprendizado com outras trabalhadoras que se aprendia o que e o como fazer. E para estes industriais somente o tempo dedicado ao trabalho garantiria a prática, o aprendizado e a qualidade do trabalho, conforme argumenta Bernardo Mascarenhas: "sem a boa e longa prática que só é adquirida com o tempo e aplicação, o trabalho produzirá pouco e imperfeito". 56

Além de externar a importância de uma operária e as dificuldades para se conseguir tal feito, as cartas acima ainda contribuem para esclarecer qual era o lugar das mulheres nas fábricas têxteis analisadas. As fábricas pesquisadas possuíam, no início de suas atividades, oito seções: a portaria, a fiação, o urdume, a tecelagem, a preparação, a tinturaria, ferraria e carpintaria. Mas era na tecelagem e em parte da fiação que as mulheres se concentravam.

No que se refere à tecelagem propriamente dita, junto ao conhecimento prático no ofício têxtil, outras características compunham o perfil de uma boa tecelã. Procurava-se por moças robustas, sadias, desembaraçadas, práticas, inteligentes e que tivessem acima de 14 anos, sinalizando a importância da compleição física da operária. Deveriam ser também ágeis o suficiente

54 MTDMM. Carta do gerente da Fábrica de São Vicente, Caixa Box n.5. (grifo nosso).

55 MTDMM. Carta do gerente da Fábrica de São Vicente datada de 18 de novembro de 1893, Caixa Box n.5.

56 MTDMM. $1^{\circ}$ relatório apresentado aos acionistas da CCC em 02 de fevereiro de 1884. 
para acompanhar o ritmo imposto pela máquina e assaz inteligentes para aprender a operá-las.

Tais habilidades parecem dizer que de fato, o trabalho na tecelagem era árduo, penoso e de difícil execução. Exigia, não só habilidades motoras e mentais, mas também certa força física para suportar o ritmo do trabalho. Assim sendo, somente moças sadias, fortes, desenvoltas e práticas podiam se ocupar da tecelagem. Uma correspondência enviada ao gerente da Fábrica de São Vicente por um diretor da CCC proporciona uma visão, mesmo que fragmentada da organização e do funcionamento desta seção:

Cada máquina terá de dar a produção para a qual foi feita. (...) Todas as repartições terão de atender preferencialmente a tecelagem, pois sendo esta o termômetro da produção qualquer atraso ocasionado a ela será prejudicial. (...) O mestre tecelão não deverá permitir que as moças saiam da fabrica para mudar de rol, esta mudança se fará imediatamente, pois antes de um tear parar o rolo cheio deve estar no chão esperando. As moças devem ser corrigidas de todos os defeitos que implicam em pequena produção, parada de tear, perda de tempo e não deve ser estorvada. A linha de trama será fornecida pela fiação por 2 pequenos que levarão a linha a cada tear trazendo de lá as espulas vazias. Se estas tiverem muita linha cabe ao menino avisar ao chefe para corrigir a tecelona. ${ }^{57}$

Diante do exposto, não resta dúvida que conseguir e manter operárias com estas aptidões acabava se constituindo como uma estratégia importante e fundamental para as fábricas, pois isto poderia ser a garantia de lucro, de bons produtos e uma forma de enfrentamento da concorrência de outras fábricas têxteis. Estas vantagens econômicas aumentavam na medida em que as operárias mais práticas e com mais destreza, consideradas as melhores dentre o grupo de trabalhadoras chegavam a operar dois teares, simultaneamente, como revelado na carta abaixo:

Tenho arranjado de modo que para o maquinismo nosso, só tenho admitido alguns meninos e umas 4 moças (do convento) para os fusos, sendo os 30 teares novos trabalhados pelas antigas operárias, uma em dois teares, nos saindo assim a tecelagem com diferença de 30 a $40 \%$ mais barato. ${ }^{58}$

Em termos salariais as tecelãs ganhavam por produção. Quanto mais tecidos produziam, maior era o salário recebido ao final do mês. Se por um lado isso implicava uma intensificação do trabalho, por outro possibilitava a estas trabalhadoras remunerações maiores que as suas colegas da fiação, principalmente aquelas que manuseavam dois teares. Nestes casos os salários recebidos por algumas delas, chegavam a ser equiparados aos recebidos por trabalhadores do sexo masculino que ocupavam cargos

57 MTDMM. Livro Copiador da Fábrica do Cedro 1916-1917, p.131-140.

58 MTDMM. Carta do gerente da Fábrica da Cachoeira datada de 23 de fevereiro de 1887, Caixa Box n.11A. 
mais valorizados. Mas vale lembrar que tais casos eram raros, pois há que se pensar que manusear dois teares não devia ser tarefa das mais fáceis, ainda mais numa jornada de trabalho de pelo menos 12 horas diárias e seis dias por semana, somente descansando no domingo e nos dias santos. Ser tecelã era o máximo que uma mulher poderia ascender hierarquicamente dentro das fábricas.

A fiação, por sua vez, era uma seção mais heterogênea, pois empregavam-se ali crianças de ambos os sexos, moças mais jovens e mesmo mulheres e homens adultos. A análise dos documentos já citados sugere que a fiação era a "porta de entrada" das operárias nas fábricas. Muitas delas chegavam em torno dos 9 ou 10 anos de idade e, se conseguissem aprender o serviço, apresentassem bom comportamento e desenvolvessem as habilidades necessárias para a tecelagem, poderiam chegar a operar os teares. Nesta seção, ocupavam-se das canelas, dos pavios, dos fusos, das bobinas e dividiam com as crianças a tarefa de limpeza do ambiente.

Em termos hierárquicos, o trabalho aí, especialmente o executado pelas mulheres e crianças, era o menos valorizado. Podemos inferir, a partir das fontes analisadas, que as tarefas eram as mais simples, monótonas e repetitivas que exigiam, a principio, pouco conhecimento técnico. Em contrapartida, as trabalhadoras deveriam apresentar disposição física e agilidade para correr de um canto a outro levando e trazendo carretéis, espulas, canelas e outras peças que abasteciam diversas máquinas como os teares e as urdideiras. E no caso das fiandeiras, propriamente ditas, sua tarefa exigia destreza com as mãos, atenção, acuidade visual, paciência e controle motor para que pudessem emendar os fios que se arrebentavam nos fusos. Uma descrição sobre o processo de trabalho nesta seção foi publicada pelo jornal Avanti! $!^{59}$ em 25 de maio de 1907:

Os bancos de fiação desenrolam aquelas fibras cardadas, dão torção e estiramento e as enrolam em muitos fusos. Mas quanta paciência requer este trabalho! Essas mulheres devem ficar sempre em pé, sempre com a máxima atenção nos 50 ou mais fusos que giram com uma velocidade vertiginosa: devem emendar muitas vezes o fio quando se rompe e consertar freqüentemente os defeitos das máquinas. ${ }^{60}$

O salário pago a estas operárias se aproximavam ao valor pago aos trabalhadores do sexo masculino considerados menos qualificados, e eram ligeiramente superiores aos pagos às crianças. Tomando-se como referência o Livro de ponto da Fábrica do Cedro de 1883 a 1885 podemos ver que as mulheres recebiam em torno de 40 a 60 réis por hora de trabalho, 0

59 Attraverso uno stabilimento di tessitura". In: Avanti!, 25 de maio de 1907.

60 Apud: PINHEIRO, P.S. e HALL, M.M. A classe operária no Brasil,1889-1930: condições de vida e de trabalho, relações com os empresários e o Estado. São Paulo: Brasiliense, 1981, v.ll (Documentos), p.164. 
que rendia uma diária de 700 réis em média. Para os homens esta hora de trabalho era em média acima dos 80 réis, possibilitando um salário diário em torno de 900 a 1.000 réis, ou seja, 20\% a 30\% a mais que as mulheres.

Em uma situação diferente estavam os trabalhadores do sexo masculino. Para eles estavam reservadas as seções e as tarefas consideradas mais qualificadas, para as quais eram exigidos conhecimentos técnicos mais elaborados, como as de chefias, as de escritório, de controle e manutenção das máquinas, as que envolviam o acabamento dos tecidos como a tinturaria, além de outras similares. Além de receberem uma remuneração maior, vez por outra, eram contemplados com premiações extras, motivadas por bom comportamento, por comprometimento, por bons serviços prestados ou por serem considerados imprescindíveis para as fábricas. Premiações que as mulheres raramente recebiam e, mesmo quando contempladas com algum "agrado financeiro", isso vinha como meio de estimular a produção e não como forma de agradecimento e reconhecimento pelo serviço prestado.

No bojo desse processo estava uma divisão sexual do trabalho organizada a partir de uma classificação dos operários entre os que eram considerados "qualificados", geralmente os trabalhadores do sexo masculino, e os "não qualificados", grupo no qual as mulheres se situavam. Analisando o processo de mecanização ocorrido nas primeiras fábricas têxteis, Concessa Macedo ajuda a entender o contexto da CCC e o significado do que seria um trabalhador qualificado e um não qualificado. Segundo ela:

Às transformações engendradas pelo sistema de máquinas, acompanham modificações em nível da divisão do trabalho. Por um lado, as máquinas exigem operários qualificados, aqueles que ficarão a cargo da manutenção e do conhecimento técnico relativo à produção. Por outro, a ampliação da divisão do trabalho requer trabalhadores especializados - não qualificados, no sentido de não deterem o conhecimento técnico de produção, bem como trabalhadores auxiliares. Estas categorias serão os novos operadores das máquinas. ${ }^{61}$

A questão proeminente aqui é que tudo isso serviu para justificar práticas de desvalorização do trabalho das mulheres em relação aos dos homens. É importante ressaltar ainda que o estudo das fontes investigadas assinala que a divisão sexual de tarefas dentro das fábricas da CCC perdurou pelos menos até 1940. Ou seja, mais de 50 anos depois da instalação primeira fábrica da $\mathrm{Cia}$, as mulheres continuavam a executar as mesmas tarefas para as quais foram requisitadas ainda no final do século XIX, isto é, ainda permaneciam como as fiandeiras e as tecelãs. Apesar de todas as inovações tecnológicas ocorridas neste período, da ampliação das seções das fábricas e da conseqüente criação de novas tarefas, as mulheres segui-

61 MACEDO, Concessa Vaz. Diferenciação ocupacional e salarial do operariado feminino "vis-à-vis" o masculino na indústria brasileira, p.18. 
ram fiando e tecendo. O que nos faz lembrar, a observação feita por um delegado operário francês, no século XVIII ao dizer: "o destino da mulher é a família e a costura (....). Ao homem, a madeira e os metais, à mulher a família e os tecidos". 62

De modo geral, estas diferenças nas condições de trabalho entre homens e mulheres é um reflexo da desvalorização pela qual as ocupações "ditas" femininas têm sofrido ao longo do tempo. A resposta dada pela Diretoria da CCC a um pedido de aposentadoria de uma operária da Fábrica da Cachoeira oferece algumas pistas da representação que os primeiros industriais têxteis mineiros tinham do trabalho executado por "suas" operárias. A carta, com data de 27 de fevereiro de 1933, foi escrita por Anna, uma operária da Fábrica do Cedro, onde faz o seguinte relato:

Operária da fábrica há mais de 38 anos achando-me agora bastante adoentada e sem recursos, venho por meio desta solicitar dos D.D. (sic) Diretores na presente reunião, baseada na magnanimidade e justiça dos mesmos, a minha aposentadoria. $^{63}$

Chamamos a atenção aqui para a resposta dada pela Diretoria ao pedido da Anna:

Indeferido a vista das informações. Operária antiga desta fábrica onde trabaIha há mais de 30 anos, sempre com interesse e assiduidade, está agora em vista dos seus serviços ocupando um lugar que não exige o menor esforço correspondendo quase a uma aposentadoria e recebe um salário de 3.400 réis diários. Quanto ao seu estado de saúde, julgamos não ser precário como alega e acreditamos também não lhe faltam recursos para seu tratamento em vista de assistência de saúde e farmacêutica que esta fábrica cuidadosamente dispensa aos seus operários. ${ }^{64}$

Analisando mais detidamente a resposta dada pela Diretoria, chagamos a pensar se o que ela realizava na fábrica era mesmo considerado um trabalho, pelos seus chefes, já que o autor da missiva deixa claro tratar-se de uma ocupação que corresponde a "quase" uma aposentadoria. Até parece algo que se faz por prazer, brincando, que não exige esforço algum, que se aprende "naturalmente", ou talvez se nasça sabendo, e a operária ainda recebe por isso.

O que parece justificar esta representação do trabalho da mulher é uma concepção que segundo a pesquisadora alemã Treusch-Dieter permeou de modo geral a produtividade feminina ao longo do tempo, e que

62 PERROT, Michelle. As mulheres ou o silêncio da história, p.171.

63 MTDMM. Caixa Box n.216.

64 MTDMM. Caixa Box n.216. (grifo nosso) 
foi incorporada à produção de fios e tecidos, a qual se assenta em três aspectos básico:

1. É um fazer contínuo, em permanente rotação. O que se produz logo desaparece e se transforma em outra coisa.

2. Parece não ter importância alguma no tempo, nenhuma relevância histórica, é um "agora contínuo", sem nenhuma noção de presente, nenhuma raiz no passado, nenhuma construção de futuro.

3. Aparentemente, é um fenômeno natural. Tudo parece mover-se sozinho, sem exigir muita assistência da pessoa ocupada. Como se o produto gerasse a si mesmo. ${ }^{65}$

Os efeitos desta concepção podem ser vistos nos baixos salários pagos às mulheres, nas tarefas monótonas e fragmentadas, na desconsideração do saber necessário a sua execução, mesmo quando exigiam moças práticas no oficio têxtil, com grande destreza e habilidades manuais. Um processo de desvalorização e de subordinação que acompanha a história da vida e do trabalho da mulher. ${ }^{66}$

\section{Considerações finais}

Para alguns autores, como Michelle Perrot ${ }^{67}$ e Domingos Giroletti, ${ }^{68} \mathrm{a}$ fábrica capitalista produziu uma racionalidade e uma ordem próprias da sociedade industrial. Perrot ainda complementa afirmando que essa nova racionalidade acabou conformando os sujeitos de acordo com os seus interesses sociais, políticos e econômicos, colocando cada sexo em seu lugar, com seus papéis, suas funções, suas tarefas, seus espaços. Disso não duvidamos.

Como vimos o lugar das mulheres nas fábricas aqui analisadas foi a fiação e a tecelagem. E a despeito da importância desses setores e do trabalho que aí se realizava, as mulheres foram consideradas trabalhadoras auxiliares. Consideradas como uma mão-de-obra desqualificada, suas tarefas se caracterizavam pela monotonia, pela repetição, pela necessidade de paciência, destreza, acuidade, agilidade, dentre outras e para as quais recebiam remunerações menores. No entanto, sua jornada de trabalho era tão intensa quanto à dos demais trabalhadores o que as tornava economicamente mais rentáveis para a Cia.

Em termos sociais tratava-se de um grupo fragilizado que encontrou nas fábricas de tecidos a alternativa contra o acirramento da miséria e as precárias condições de vida. Aprenderam a ser operarias têxteis no dia-a-

65 Apud: MACHADO, Ana Maria. O Tao da teia: sobre textos e têxteis. Estudos Avançados, v.17, n.49, p.181, 2003.

66 SURELLOT, Évelyne. A mulher no trabalho.

67 PERROT, Michelle Os excluídos da história: operários mulheres e prisioneiros. Rio de Janeiro: Paz e Terra, 1988

68 GIROLETTI, Domingos. Fábrica, convento e disciplina. 
dia da fábrica, trabalhando com dedicação e servindo à fábrica de modo exemplar. Eram as trabalhadoras mais constantes e assíduas, e dada às condições sociais em que se encontravam, submetiam-se melhor à dominação, ao controle e à vigilância patronal e masculina imposta por estes estabelecimentos.

As operárias encontram nas fábricas um cotidiano de opressão, desvalorização, exploração, menos autonomia e liberdade do que os trabalhadores do sexo masculino, uma dupla vigilância dos patrões e das regentes dos conventos e quiçá de seus companheiros de trabalho, enfrentaram o isolamento e a reclusão dos conventos, dentre outras coisas. Por tudo isso puderam ser consideradas "os melhores empregados".

Entretanto é importante salientarmos que em meio a tudo isso e por meio de tudo isso, elas também encontraram nas fábricas e na figura dos gerentes a proteção, que muitas necessitavam. Proteção essa que se materializava, dentre outras coisas, nos conventos das fábricas e no zelo pela integridade física e moral das operárias, refletido nas atitudes paternais e patriarcais dos gerentes.

Sem dúvida trata-se de um cotidiano complexo, denso e muitas vezes contraditório, mas que expõe o espaço da fábrica como um espaço de relações sociais que cumpre um papel de socialização, de formação de identidades e, muitas vezes, de conformação dos sujeitos, a partir de valores e modelos construídos e valorizados pela sociedade.

Deste modo, consideramos importante assinalar que todo o processo de inserção e formação para o trabalho pelo qual passaram as mulheres, e o cotidiano vivido por elas nessas fábricas têxteis, veio entremeado também por aspectos que dizem respeito às relações de gênero. Não podemos nos esquecer dos conventos ali organizados somente para elas, da vigilância maior a que foram submetidas, do cerceamento da liberdade e da autonomia, do reforço às qualidades morais e ao bom comportamento, considerados como atributos femininos, os quais eram exigidos das operárias.

É certo que a vigilância, a disciplina e o controle foram alguns meios empregados pelos gerentes e proprietários com todos os trabalhadores de modo geral. Porém no caso das mulheres, como vimos, tais artifícios adquiriram conotações singulares e diferenciadas, pois nada semelhante a um convento foi encontrado para abrigar os operários do sexo masculino. Ademais, não podemos nos esquecer de que nas nascentes fábricas de tecidos eram os homens que comandavam e, às mulheres, não restava muita coisa além da obediência.

Ver a fábrica a partir da perspectiva do gênero é ter consciência de que se trata de um espaço social, político e de poder, onde as diferenças entre homens e mulheres acabam por submeter os sujeitos a determinadas conformações, papéis sociais, lugares e estereótipos. Conforme nos 
alerta Guacira Lopes Louro ${ }^{69}$ as instituições e as práticas sociais, às quais engendram, são constituídas pelos gêneros e como tal acabam "fabricando" os sujeitos ao mesmo tempo em que são "produzidas" por estas representações. Ainda de acordo com a autora essas instituições "têm gênero, classe e raça".

Mas, não há como negar que a despeito destas condições, as fábricas possibilitaram o emprego, o salário, a moradia, a proteção e até certo ponto a dignidade de vida, coisas tão necessárias às trabalhadoras naquele contexto social e cultural. Todavia, mesmo sem o devido reconhecimento, as mulheres foram capazes de surpreender, conquistando o seu lugar nas fábricas fazendo uso do talento que souberam desenvolver ao longo tempo, mesmo que isso, ao que parece não tenha sido valorizado.

69 LOURO, Guacira L. Gênero, sexualidade e educação: uma perspectiva pós-estruturalista. $8^{a}$ ed. Petrópolis, RJ: Vozes, 1997, p.88. 